\title{
Ardeth
}

A magazine on the power of the project

$7 \mid 2020$

Europe

\section{Moving Ground}

The Construction of AlpTransit Infrastructure and its Monumental Landscapes

Chiara Pradel

\section{CpenEdition}

1 Journals

Electronic version

URL: https://journals.openedition.org/ardeth/1808

ISSN: 2611-934X

Publisher

Rosenberg \& Sellier

Printed version

Date of publication: 1 December 2020

Number of pages: 67-83

ISSN: 2532-6457

Electronic reference

Chiara Pradel, "Moving Ground", Ardeth [Online], 7 | 2020, Online since 01 June 2021, connection on 25 June 2021. URL: http://journals.openedition.org/ardeth/1808 


\section{Moving Ground. The Construction of AlpTransit Infrastructure and its Monumental Landscapes}

Chiara Pradel

Abstract

Infrastructures as high-speed railways are a contemporary debated topic with political, economic and environmental impacts. In the Alpine arc alone, located in the heart of Europe, as of today six HSR lines are planned or have been realized.

Within this framework, the article probes the case of the New Rail Link through the Alps that connects Germany to Italy through Switzerland. This "Infrastructural Monument” in fact produces a number of ground movements that are affecting and shaping the ever-changing Swiss mountainous landscapes: millions of cubic meters of excavated material arising from tunnelling and construction activities are spread among the railway's nearest territories.

What could be the role of design and landscape architecture? This research is intended as an instrument to deepen the design meaning of moving ground actions, reflecting on how, millennia after the first ancestral earth mounds, these monumental earthworks could today become part of a continuously renewed poetic imagination.
Affiliatio

Politecnico di Milano, Dipartimento di Architettura e Studi Urbani

Contacts: chiara [dot] pradel [at] polimi [dot] it

Received:

21 April 2020

Accepted: 16 December 2020

DOI: 10.17454/ARDETH07.05

\section{ARDETH \#07}




\section{Even the etymology of the term "Landscape", refers to the earth shovelled and shaped for human life.}

Moving ground: from construction sites to landscape, between memory and imagination

The process of re-shaping the land with earth has had (and still has) great consolidated implications for metropolitan, urban, rur-urban and agricultural life: sacred, social, ecological, artistic, political and economic (Bourdon, 1995). Within the architectural field, the ancient act to shape and move the ground was mentioned by Gottfried Semper inside his Four Elements of architecture, along with the other first and original signs of human settlements: "hearth" (ceramics), "roof” (carpentry), "weaving” (walling) and, finally, "mound" (earthworks) (Semper, 2011: 102), where the latter refers not only to the planning of the basement of a building, but also recalls the deeper meaning of the founding ancestral contact with the earth and the penetration of the ground to dig or heap it. Even the etymology of the term "Landscape", according to John R. Stilgoe, refers to the earth shovelled and shaped for human life (Stilgoe, 2015: IX). This interpretation of the meaning of the word gives an enlightening significance to a discipline, through which we unceasingly interact with the terrain, re-thinking and modeling

our evolving and living ground.

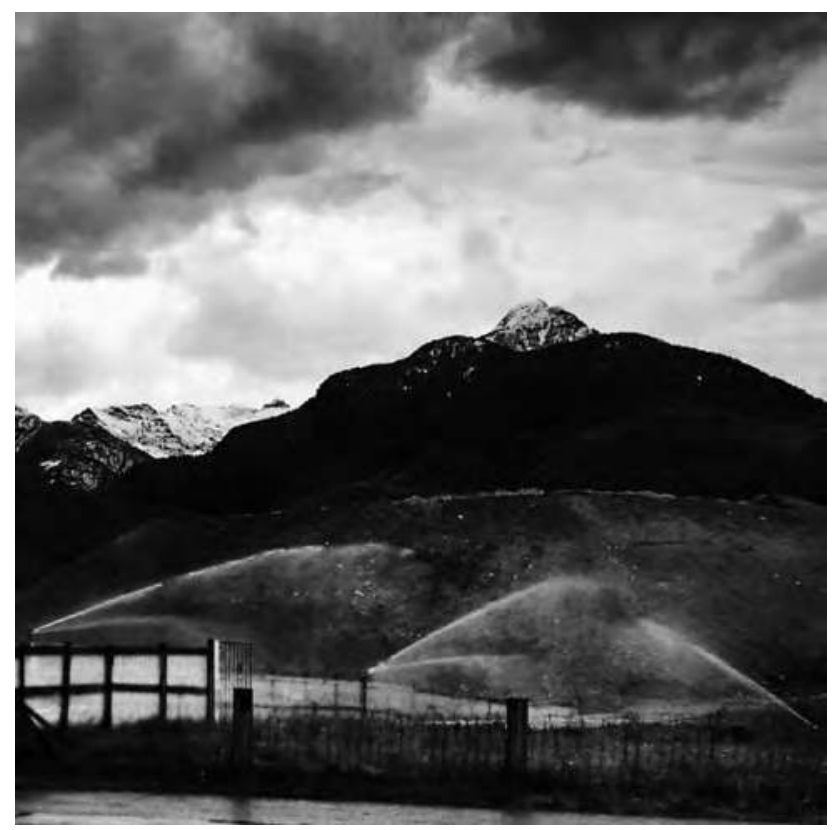

Fig. 1 - Earthworks, Biasca, 2012. Photo by the author.

The observation of the inert materials coming from the tunneling activity functions as a first act of critical recognition through an inductive approach, which starts from an interaction with the treated morphological phenomena and leads to an imaginative understanding of places. 
An observation of landscapes affected by depots or by relevant ground modifications on the one hand easily leads to an initial recognition of both the physical and inspirational aspects of earthworks - between retentissement, memory and imagination (Bachelard, 1969: 19) - and of their powerful effects in the perceived intimate space (Kentridge, 2014: 69-98), as "this grandeur is most active in the realm of intimate space. For this grandeur does not come from the spectacle witnessed, but from the unfathomable depths of vast thoughts" (Bachelard, 1969: 193). Earthworks reinterpretation has indeed elicited a prominent redefinition of the ground movements meaning inside the expanded field of landscape, of sculpture, of architecture (Krauss, 1979).

On the other hand, the movement of materials that are dug, collected and deposited inside landscape is emerging as one of the most important and considerable secondary effects of building activity, which involves an increasing amount of earth and soil resulting from the construction and demolition of walls, houses, infrastructures, derelict edifices, roads or rails.

A huge number of landfills are silently entering the territories that one normally lives and perceives; depots are appearing and transforming valleys, natural areas, villages and urban peripheries.

This topic is relevant both on a local, site-specific scale - for example, in Tessin alone, a Swiss mountainous canton that measures less than $3000 \mathrm{~km}^{2}$, according to the 2019-2023 Waste Management Plan there are 31 depots already functioning or soon to be opened - and on a global scale - let's consider policies such as the $7^{\text {th }}$ Environment Action Program (EAP) and Waste Framework Directive (2008/98/EC) that have set the goal to recover 70 per cent of waste from non-hazardous construction sites -. As in Tessin, earth depots have given rise to an increasing controversial idea of landscape in many other contexts linked to recent great and impactful construction activities. Public debates - whether they are linked to a sense of beautiful picturesque panoramas completely ruined by the depots, to an idea of disrupted ecology that needs redemption (Iovino, 2016) or to a presumed original topography disturbingly altered by the building activities (Dixon Hunt, 2016) - often raise doubts about

\section{A huge number of landfills are silently entering the territories that one normally lives and perceives.}




\section{The minimization of the amount of waste, don't seem to be enough and could be dangerously considered as adequate.}

public health, carelessness of natural, cultural and historical heritage, inequalities in peripheral areas and contempt for landscape aesthetics. Very rarely are ground movements perceived as challenging opportunities inside an endlessly changeable nature or as places of flexibility, where there could be an attempt to relate the buildings or infrastructures construction activities with renewed ecological systems, avoiding any form of domestication or intransigent dialectical opposition between artificial and natural.

Moreover, even if the question of reconsidering ground-based actions is highly related to earth management practices, to soil resources assessments, to environmental and sustainability programs, the minimization of the amount of waste, or other similar attitudes like impact-reduction, limitation and camouflage, from an architectural point of view don't seem to be enough and could be dangerously considered as adequate, definitive solutions, leading to an acceptance of "poorly designed systems", while inducing an "ultimate failure of 'the be less bad approach': a failure of the imagination” (Braungart, McDonough, 2009: 43).

Rethinking inert materials in architecture and landscape architecture, a synthetic framework

Although the reuse of inert materials in a more organized and systematic way started around the 50s, up until now the major innovative researches on this topic have been primarily addressed to findings linked to technological advancements, or to the need to reuse inert waste for high-quality concrete production and shotcrete aggregates (Anagnostou, Ehrbar: 2013), to environmental practices for land reclamations along rivers, lakes and bays - in Cleveland, New York, San Francisco, Toronto and many other places -, or directed to meaningful artistic expressions, as in the works of Herman Prigann, Michael Hezier, Robert Smithson or John Latham, that still powerfully influence the architectural process.

Nevertheless, during the early 70s and in the 80s as well, the sample work of some architects especially engaged with ecological approaches and environmental problems - one may recall the Olympia Park by Gunter Grzimek in Munich and the Irchelpark in Zurich by Eduard Neuenschwander - or the informal 
reappropriations of pieces of land by collective movements of citizens, inhabitants and activists - as in the Stettbacher Allmend in the Zurich outskirts - have contributed to emphasize the existing link between consumption of natural resources, landscapes and (infrastructural) construction activities. More recently the practice and the research of landscape architects like, among others, Enric Battle and Joan Roig, Paolo Bürgi, James Corner, Peter Latz, Christophe Girot and Martha Schwartz have made it increasingly apparent that to organize and to re-think inert deposits or quarry fills, to plan new outdoor temporary inert storage areas for sizeable to small building sites, to plan the conversion of an amount of rubble into soil, are issues that affect the landscape not only after the act of filling and moving inerts during a huge construction activity or on reflection and a posteriori, but, according to an ecological approach, should also precede and accompany the process itself, as a generative and creative complex strategy of intervention.

In spite of the increasing interest and awareness of the relevance of the topic, as one could easily verify through the study of small to medium building interventions, the fragmented nature of common construction and demolition practices, the standardized procedures and the lack of geographical and temporal overlap between different ground activities make it quite difficult to implement the rethink and reuse of debris at a significant design level. For this reason, it is interesting to consider, in particular, big scale infrastructural oeuvres, which should inevitably face relevant problems and clarify design approaches and policies in a concrete and strategic way, thanks to landscape design interventions closely coupled with the construction phase and the development of the infrastructural site. Exemplary in this sense are the approach of Bernard Lassus to accompanying the realization of the A11 autoroute or the attempt of the High Speed 1 landscape-engineering project team to improve the visual integration of the Channel Tunnel rail link in the English rural context through slopes made by reused soil or the creation of a wildlife reserve island made by the material excavated in the London's Crossrail train project. Especially in the Swiss context several road, railway and highway interventions have had to interact with different extreme topographies or
The fragmented nature of common construction and demolition practices make it quite difficult to implement the rethink and reuse of debris at a significant design level. 
Fig. 2 - Landscape

script along

AlpTransit rail line

and sections of

Gotthard and Ceneri

Tunnel. Drawings by

the author.

From top to bottom:

Delta Reuss, Erstfeld,

Amsteg, Sedrun,

Faido, Bodio, Biasca,

Camorino, Sigirino,

Lugano Vezia. In

these sites the NRLA

construction process

has become evident

thanks to relevant

ground movements

inside landscape.

\section{While the}

underground

infrastructures

imply, the

protection of

the overground

territories and

trans-national

natural heritage.

\section{The increasing \\ tunneling activity \\ is producing \\ broad volumes of \\ excavated earth.}

to fit into fragile landscapes; from the historical 62-km Abula Line, an early masterpiece of engineering and architecture in railway-building that climbs the mountain territory of the Canton of Graubünden through spiral tunnels and four valley-crossing viaducts, to the recent project to cover with spoils a long portion of the A2 close to the Gotthard Pass, in order to better camouflage the motorway in the valley floor.

The intent to study complex building sites, such as NRLA ones, is thus directed to the observation of great earth movements that fiercely affect the surrounding territories, pushing for the urgent and relevant quest on the extensive effects on landscape of the construction of new access points, tunnels, portals and, more importantly, on the role of landscape design in relation to these earthworks.

\section{AlpTransit landscapes}

According to the definition of Infrastructural Monuments (MIT Center for Advanced Urbanism, 2016) - like the highspeed networks that are currently planned and partially realized in Europe - infrastructures are conceived as open, inclusive objects, as both common spaces and Megaforms (Frampton, 1999) that, in addition to the realm of the transportation of goods and labor, synthesize surrounding landscape, public space and architecture. Moreover, if the first generation of infrastructure was for the greater part built in the overground space, now we are more and more able to drive them underneath: today in Switzerland alone there are around $2000 \mathrm{~km}$ of tunnelled traffic and water connections. While the underground infrastructures imply, as one of the claimed main priorities, the protection of the overground territories and trans-national natural heritage, thanks to tunnels that pass underneath mountains, valleys, cities, villages and natural protected areas, avoiding having to cross them by routes, bridges and overpasses and preventing a significant amount of overground traffic, as a downside, the increasing tunneling activity is producing broad volumes of excavated earth. In the Alpine region, just the tunneling work of the 57km-long Gotthard axis for the AlpTransit railway, for example, originated more than 13.3 million cubic meters of earth and rocks.

Therefore, during the last 20 years the AlpTransit spoil management has played a significant role in the 


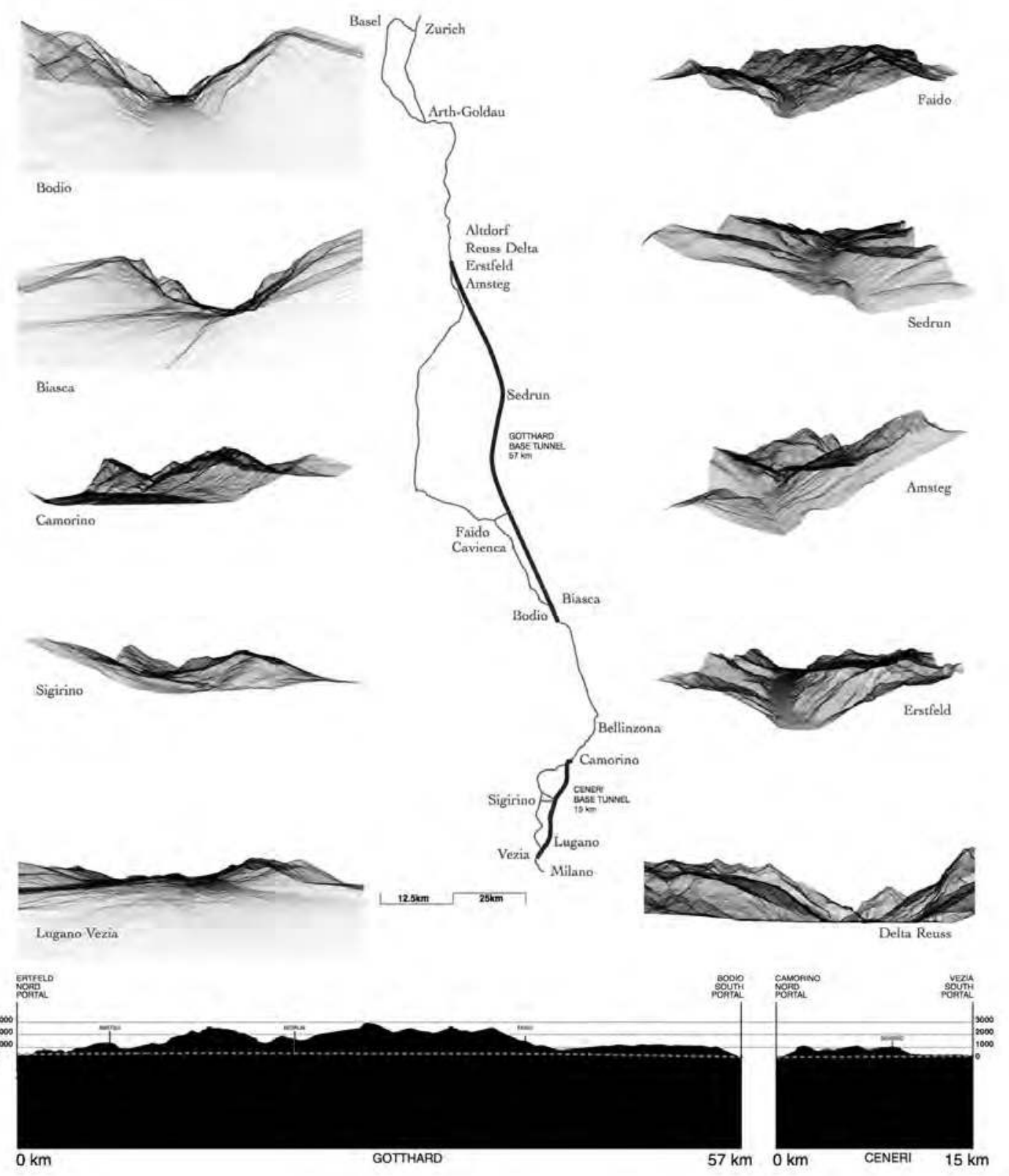




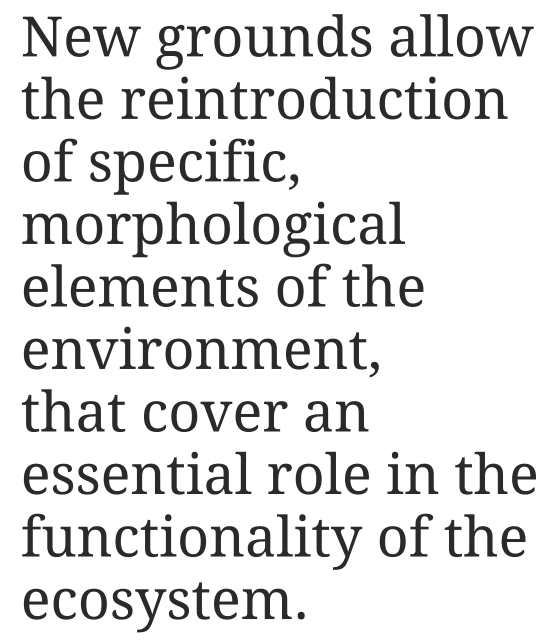

A decision was made to create an artificial lake on top of one of the latest depots and to open it to the public, thanks to a landscape design intervention that took advantage of the new morphology of the hilly landscape. research on the development of more environmental-compatible solutions, in the attempt to limit sound, dust, transport and environmental emissions, thanks to the creation of new water surfaces, new planted areas and ecological corridors near the railway line (Lanfranchi et al., 2019). On the one hand, indeed, "the construction of a large infrastructure project must include the sacrifice of extensive portions of territory and ecologically fragile spaces” (Lanfranchi et al., 2019: 405), while on the other hand, with a kind of compensative attitude, ground-based interventions such as the Reuss Delta renaturalization or the Sedrun intermediate attack location, reuse excavated soil on the basis of the fundamental codes of environmental phenomena and processes, trigging both natural and human transformation scenarios.

In Erstfeld, Canton Uri, about 3.3 million tons of lower quality aggregates were transported by train and then by ship to be used to fill the mouth of the river Reuss to promote the natural process of depositing the delta, which was in critical condition due to the strong erosion caused both by the deviation of the river route and the excavations for the extraction of gravel which occurred during the 80s. These new grounds allow the reintroduction of specific, morphological elements of the environment or recreate structures, like ecological corridors or wildlife passages that cover an essential role in the functionality of the ecosystem.

Similarly, the Sedrun intermediate attack location occupies about $375000 \mathrm{~m}^{2}$ near a small touristic alpine village in the Graubünden Canton allowing for the realization of emergency stopping stations and the excavation of the Gotthard Base Tunnel during a remarkably long period of about 20 years. After the completion of the infrastructural intervention, the previous topography of the site resulted altered not only inside the installation zone - that is the one closest to the access tunnel - but also in some neighboring depots and temporary embankments areas. Moreover, since the tunnel construction generated more excavated soil than planned, a decision was made to create an artificial lake on top of one of the latest depots and to open it to the public, thanks to a landscape design intervention that took advantage of the new morphology of the hilly landscape.

But, over all the ground-based operations and some restorative landscape measures taken to improve the 


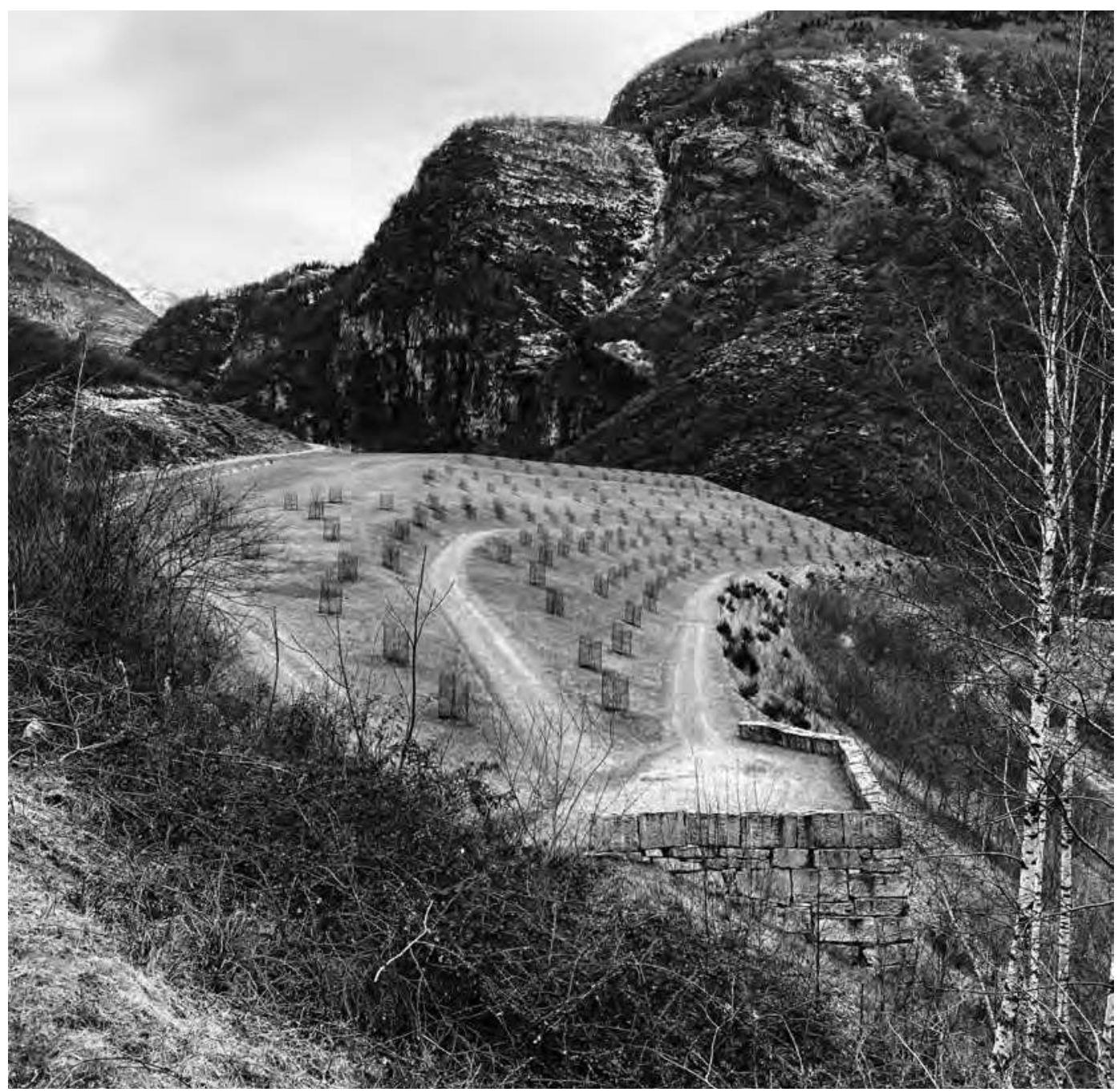

final layout of sites, as in Erstfeld or in Sedrun, only the Sigirino depot intervention has been the subject of a structured design research during the projectual and constructive phase more specifically framed within the Landscape Architecture field, thanks to an analysis conducted by Atelier Girot, together with ETH landscape students, based on geo-referenced point cloud models (Girot et al., 2013).

Nonetheless, it is still possible to affirm that the infrastructure construction is in essence "done by people other than landscape architects”, leaving little room for landscape spatial experience, reading or tactile

Fig. 3 - Biasca, 2020.

This site collects more than $3.2 \mathrm{mn}$ tons of material. The spoils form a sort of plastic extension of the dejection cone, from Mount Crenone towards the valley. Part of the area is in the process of reforestation, while another part remains open to subsequent deposits.

Photo by the author. involvement (Corner, Bick Hirsh, 2014: 162). 


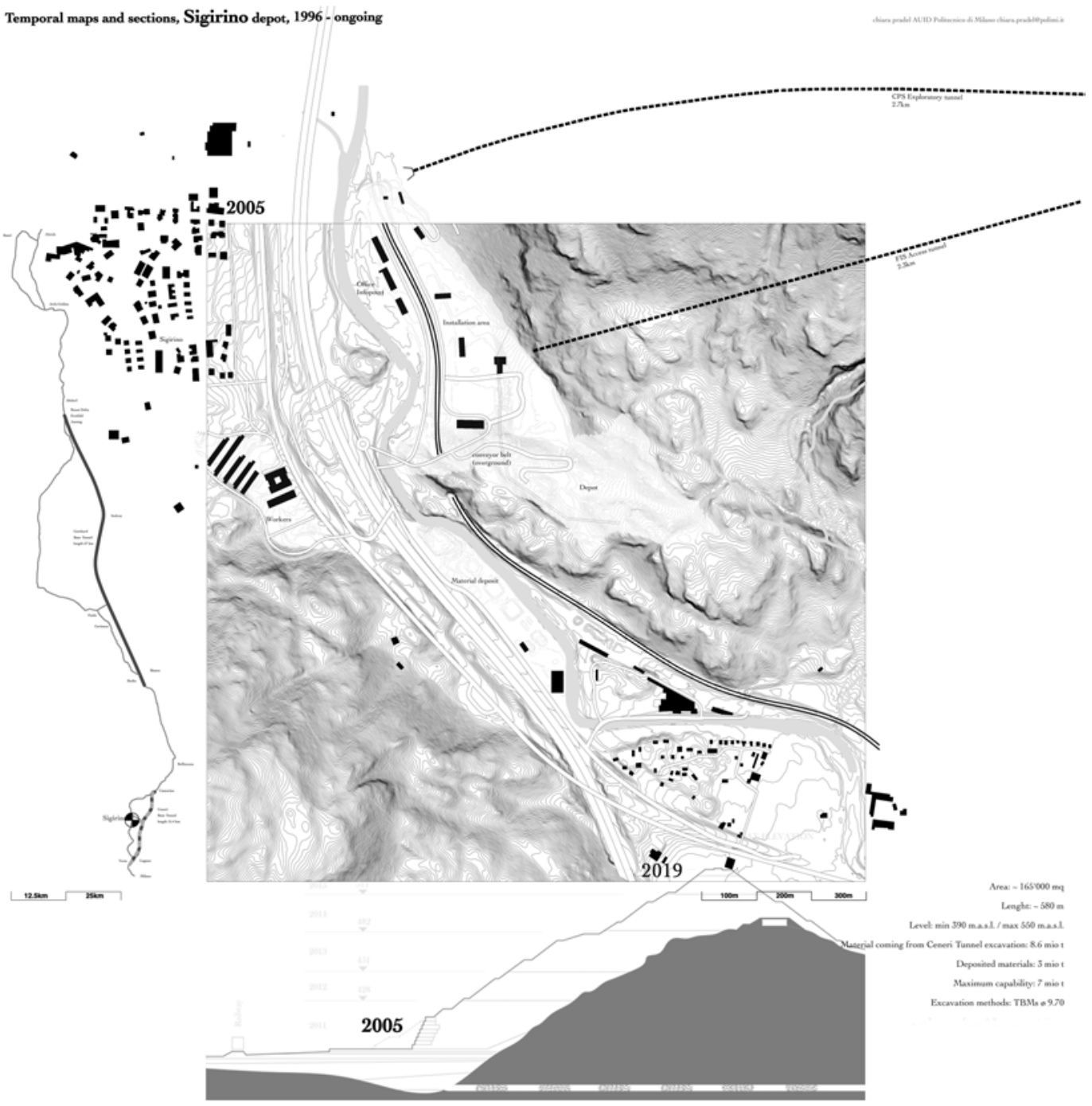


Temporal maps and topological drawings

The need for a "landscape spatial experience" became clear not only during the first phase of the research, the observation of NRLA selected sites, but also during the following data analysis and the study of the official documents produced for the construction project. For example, while the engineering or geologic drawings are made by fixed, schematic and clearly defined geometric forms, spatial limits of the affected areas are, in reality, uncertain and unclear. Often disposal sites, especially when set against mountains, are partially open rather than clearly bounded and their constructed forms, after some time, appear as natural elements grown in the landscape, instead of artificially figured ground movements. The analyzed earthworks are, moreover, similar to ongoing settlements rather than pre-established, pre-organized constructions inside coherent places, not only during the construction phase, but also subsequently due to possible erosion phenomena, the settling of the ground or the frequent further deposits of waste material from different construction sites. These areas interact simultaneously with the anthropic presence while they engage with temporalities of geologic and landscape elements that are of quite different or outof-human-scale dimensions. Therefore, there is an inevitable, strong disconnect between design documents that refer mainly to regional planning procedures, to land uses, to mobility, to the remarkable and powerful technical solutions adopted or to the environmental restoration but, for example, neglect to express how sites impact the imagination or trigger in term of sequential landscape experiences.

The excavated soil coming from the tunnels of the NRLA appears as a fluid material that follows the construction activities and is placed between the rigid geometries of the machines, the complex structures of the construction sites, the unavoidable needs of technical-engineering management and the evolving orography of the land that hosts them. Thus, it releases itself from the consolidated registers of formal evaluation of the architectural language or of the usual dimensional and structural definition of engineering work. Rather, it is more immediate to refer to a sort of arcane primitiveness of the gesture that shapes, tilts, distorts, throws and contains at the limit of the
Fig. 4 - Panel $(4 / 16)$

from the Sigirino

temporal map, intermediate stage, 2005. Drawing by the author. As in Biasca, in Sigirino as well there is an attempt to camouflage the huge earthworks, putting them near the mountains and seeking to restore, through a re-engineered forest extension, a kind of aesthetic of naturalness.

\section{While the engineering or geologic drawings are made by fixed, schematic and clearly defined geometric forms, spatial limits of the affected areas are, in reality, uncertain and unclear.}




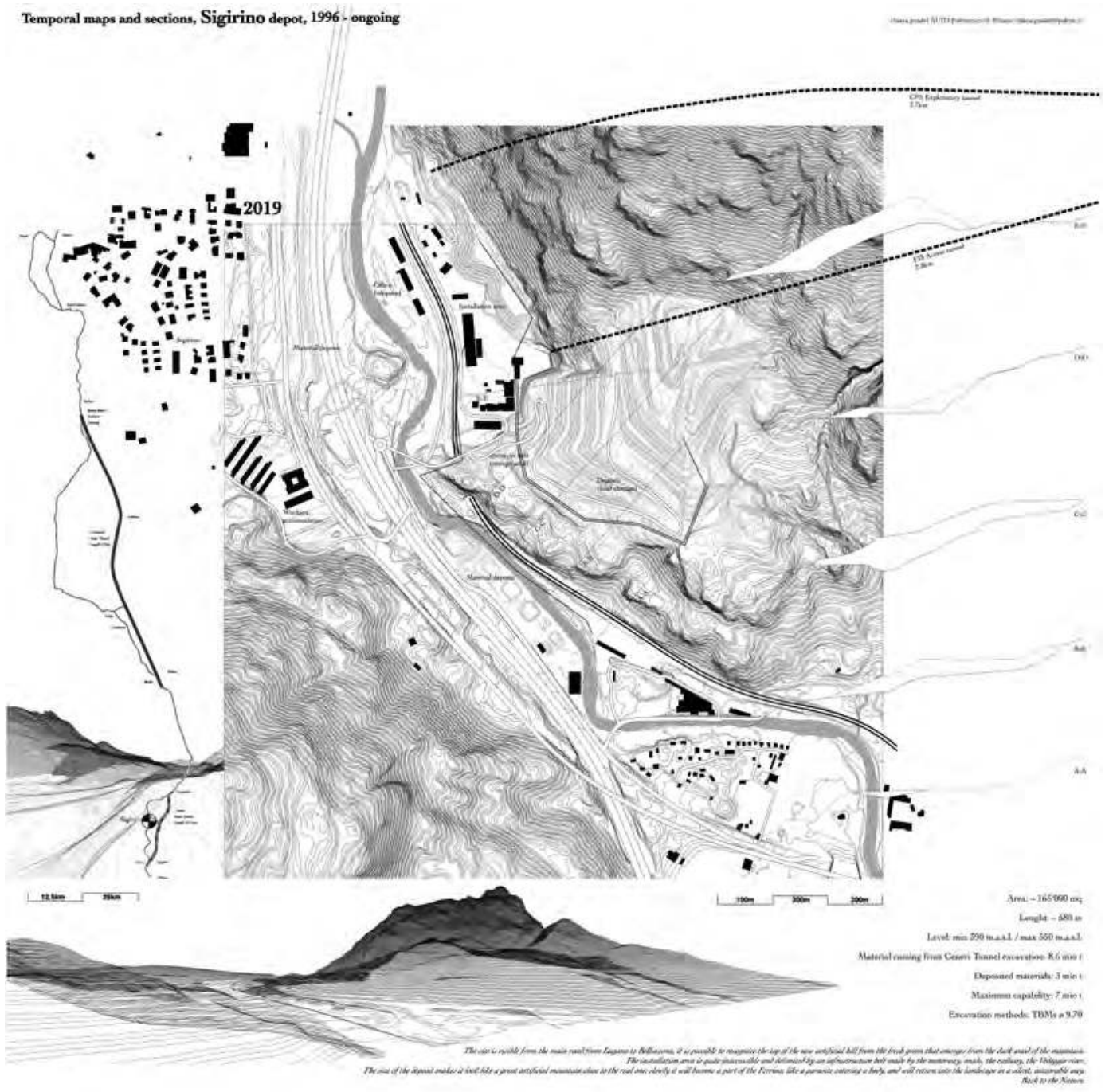


dissolution of the figurative or the recognizability of the anthropic gesture.

The research process therefore uses drawings as a narrative, visual essays that work retrospectively, looking at the various intermediate stages of the disposal process, while also trying to evoke the "afterlife" of places (Dixon Hunt, 2004). They first act through a critical de-composition, that is an attempt to understand the structure of Landscape and the physiognomy of the ground far beyond the act of seeing. The sites are treated as texts that include the possibility of writing and geographically reading landscapes (Besse, 2000) as drawings could be considered as a sort of white writing, a primary zero degree (Barthes, 1990) that would make this decomposition a possibility for understanding the site and of a renewed creative process.

In particular, temporal maps made by plans, sections, pictures and schemes are tools that follow the constantly changing nature of landscapes and frame moments that clearly refer to an uninterrupted sequence. They become instruments to describe and to understand the dimensions (volume, surface, difference in level, etc.) of the new artificial grounds and to critically interpret their evolving relationship with the surrounding urban or natural settlements, with the pre-existing geographical conditions, with the human activities and practices (most of the time a spontaneous and informal way of re-appropriating spaces), with the environmental restorations and, above all, with topography.

Together with Temporal Maps and sections, Topological drawings behave as figurative tools that aim to express the figurative, intangible potentiality of sites. They serve as morphological instruments to "trace praxis" (Leatherbarrow, 2004: 251) of ground movements inside landscape before, during and after the realization of the infrastructure, focusing both on a territorial level and on a smaller scale while searching for a middle ground between the extremes of abstract interpretations and of contextual thoughts, between modes of seeing and objectivity.

These visual representations function as a form of research on the plastic substratum of landscape, of its hidden latencies and of its distinctive resulting shapes (Besse, 2000), focusing on a surface, where the intertwining of histories and geographies emerges and the depth of the soil is brought to light. Finally, drawings
Fig. 5 - Panel (5/16) from the Sigirino temporal map, intermediate stage, 2019. Drawings by the author. Non-hazardous material has been deposited against the Ferrino Mountain, several steps have been created and greened up. The depot will be the highest Swiss artificia mountain and will contain about $7 \mathrm{mn}$ tons of material.
Temporal Maps
and sections,
Topological
drawings behave
as figurative tools
that aim to express
the figurative,
intangible
potentiality of sites. 
Fig. 6 - Panel (12/16)

from the Sigirino topological drawings, intermediate stage, 2016. These drawings aim to underline the indeterminacy (in their various forms and in their different instances) of ground movement processes and suggest possible patterns, imaginative interpretations and connections focusing on their inner latent, formal structures.

Drawing by the author. lead to a different kind of knowledge: an epistemological contribution that supplements and enriches our understanding of science, nature and architecture (Agrest, 2018) and introduces new compositional urgencies.

\section{Monumental Grounds, Open Conclusion}

The research, through the analytic observation, the critical de-composition, the temporal maps and topological drawings, fosters a critical attention to the understanding of landscape spaces resulting from ground movements during construction activities of infrastructures and interprets the effects of contemporary constructive actions on landscapes.

AlpTransit ground interventions could be understood as new states of space.

The analysis and drawings lead to possible interpretations of emerging landscapes in terms of figurative inventions and topological relationships, blurring their figuration within the dialogue among ecology, technique, and culture.

The design approach to the moving ground infrastructural sites indeed appears to be placed between:

A challenging topological site transformation, made by traces of construction activities, efficient earth management systems (linked to the excavation 
system, the transportation system, the water management system, etc.) and high technological solutions linked to the infrastructures. The study of areas such as Sigirino highlights how landscape-oriented interventions could inspire (technical) changes in infrastructure construction fields and vice versa.

New constructed ecologies that, in a completely artificial environment, imply the creation of dynamic spaces which could extend the boundaries of infrastructural interventions to the multitude of nonhuman beings and generate the specific morphology, heterogeneity and performativity of natural environments. As in the Delta Reuss reclamation process, inert waste disposals are no longer conceived as a mere passive object inside a Kantian natural beauty to be redeemed, but rather elements than can nourish both the design meaning and the ecologic character of the landscape intervention (Braae, 2015; Rocca, 2006: 10). Constructed ecologies thus shift "from thinking in terms of a stable nature and a destabilizing humanity to work with an unstable and changing nature" (Grose, 2017: 13-14), New forms emerging from deep cultural strata made by strong symbolic presences and historical meanings, new virtual and real networks, altered relations between underground and overground landscapes, between human present time and geological past, human scale and natural scale. Finally, the critical analysis and the research by drawings on AlpTransit construction sites, access points and deposits lead to an haptical (De Sanna, 1976: 5) interpretation of landscapes, staging their irretrievably unpredictable, fragile and monumental aspect.

Unpredictable, because of the unpredictability of the material behavior, since, for instance, excavated soil properties could be known and fully understood only empirically, during the landscape construction process, and because of the varying amount of spoils that, especially during infrastructure realization phases, could easily change over time.

Fragile, as these ground movements temporarily disclose the casual, ephemeral beauty that sometimes arises in spaces where the absence of a standard project occurs, of a plan that follows the codified human management of architecture and landscapes.

Monumental, in the sense that there is evidence of a "no longer historical, but geographical" monumentality (Cache, 1997) of the moved ground, that powerfully emerges from the hidden, underground construction process and sculpturally shapes the surface of the Earth.
The study of areas such as Sigirino highlights how landscape-oriented interventions could inspire (technical) changes in infrastructure construction fields and vice versa. 


\section{References}

Agrest, D. (2018), Architecture of Nature. Nature of Architecture, New York, Applied Research and Design Publishing. Anagnostou, G., Ehrbar, H. (eds) (2013), Tunnelling Switzerland, Zurich, Hochschulverlag.

Bachelard, G. (1969 [1957]), The Poetics of Space, Boston, Beacon Press.

Barthes, R. (1990 [1953]), Writing Degree Zero, New York, Hill \& Wang.

Berger, A. (2006), Drosscape. Wasting Land in Urban America, New York, Princeton Architectural Press.

Besse, J. M. (2000), Voir la terre. Six essais sur le paysage et la géographie, Arles, Actes Sud.

Bourdon, D. (1995), Designing the Earth. The Human Impulse to Shape Nature, New York, Harry N. Abrams.

Braae, E. (2015), Beauty Redeemed. Recycling Post-industrial Landscapes, Basel, Birkhäuser.

Braungart, M., McDonough, W. (2009), Cradle to Cradle.

Re-making the Way we Make Things, London, Vintage.

Cache, B. (1997), Terre Meuble, Orléans, HYX.

Corner, J., Bick Hirsch, A. (2014), The Landscape Imagina-

tion: Collected Essays of James Corner 1990-2010, New York, Princeton Architectural Press.

De Sanna, J. (1976), Aptico. Il Senso della Scultura, Crusinallo, Edizioni Alessid'après.

Dixon Hunt, J. (2004), The Afterlife of Gardens, Philadelphia, University of Pennsylvania Press.

Dixon Hunt, J. (2016), Site, Sight, Insight, Philadelphia, University of Pennsylvania Press.

Frampton, K. (1999), Megaform as Urban Landscape, 1999 Raoul Wallenberg Lecture, New York, The University of Michigan.

Girot, C., Freytag, A., Kirchengast, A., Richter, D. (2013), Landscript 3 Topology, Berlin, Jovis.

Grose, M. (2017), Constructed Ecologies. Critical Reflections on Ecology with Design, London and New York, Routledge.

Iovino, S. (2016), Ecocriticism and Italy: Ecology, Resistance, and Liberation, London, Bloomsbury Academic Press.

Kentridge, W. (2014), Six Drawing Lesson, London, Harvard University Press.

Krauss, R. (1979), Sculpture in the Expanded Field, "October”, n. 8, pp. 30-44.

Lanfranchi, P., Catelli, E., Bühler, T. (2019), Environmental reclamation for the Gotthard Base Tunnel, effects of spoil management on landscape, in D. Peila, G. Viggiani, T. Celestino (eds), Tunnels and Underground Cities: Engineering and Innovation meet Archaeology, Architecture and Art, London, Taylor \& Francis Group, pp. 404-414.

Leatherbarrow, D. (2004), Topographical Stories, Studies in Landscape and Architecture, Philadelphia, University of Pennsylvania Press.

MIT Center for Advanced Urbanism (eds), (2016), Infrastructural Monument, New York, Princeton Architectural Press.

Rocca, A. (2006), Natural Architecture, New York, Princeton Architectural Press. 
Semper, G. (2011 [1834]), The Four Elements of Architecture and Other Writings, trans. H. Mallgrave, W. Herrmann, Cambridge (MA), Cambridge University Press.

Stilgoe, R. (2015), What is Landscape?, Cambridge (MA), The MIT Press. 